\title{
Humanizing Organizations: Researchers as Knowledge Brokers and Change Agents
}

\author{
Robin Beers \\ Wells Fargo Bank, N.A.
}

\begin{abstract}
Competitive pressures and more empowered customers have made customer experience a critical strategic imperative for every industry and every company. The need for research about people, their experience, and how they define value has increased as businesses change to become more customercentric. Researchers must become more than purveyors of insight; they must also act as knowledge brokers and change agents. This paper describes how research combined with user-centered design and facilitation techniques bring benefits to business beyond customer understanding, including alignment on complex, multifunctional teams, project scope clarity, and a strategy for risk mitigation in a world exploding with change.
\end{abstract}

\section{AS BUSINESS BECOMES MORE CUSTOMER-CENTRIC, THE NEED F OR INSIGHT INCREASES}

Competitive pressures and more empowered customers have made customer experience a critical strategic imperative for every industry and every company. The need for deep understanding about people, their experience, and how they define value has increased as businesses change to become more customer-centric:

Imagine a crazy wonderland where most of what you learned in business school is either upsidedown or backward - where customers control the company, jobs are avenues of self-expression, the barriers to competition are out of your control, strangers design your products, few features are better, advertising drives customers away, demographics are beside the point, whatever you sell you take back, and best practices are obsolete at birth; where meaning talks, money walks, and stability is a fantasy; where talent trumps obedience, imagination beats knowledge, and empathy trounces logic. (Neumeier, M., 2008)

In today's disruptive economic and industry landscape, incremental improvement leaves companies - and whole industries - vulnerable to competitive threats and total disintermediation. As customers become more connected and empowered, and traditional sources of competitive dominance no longer suffice, "the only sustainable competitive advantage is knowledge of and engagement with customers" (Cooperstein, 2013).

Forrester Research calls this era of customer-focus "The Age of the Customer." Humanize authors Notter \& Grant proclaim that in business "we have begun to witness a revival of the importance of being human" $(2012$, p. 3). And author and strategist, Nilofer Merchant, describes this as the "Social Era" where companies need to "take in market signals for what customers want, how they want it, where and 
when they should be able to get it, and how much they are willing to pay" (Merchant, 2012, Digital Location: 405 of 1229). No matter which label we use, this is a time that requires companies get closer to people to understand how their current and potential customers define value.

\section{CUSTOMER EXPERIENCE AS A STRATEGIC IMPERATIVE REQUIRES ORGANIZATIONS TO DEVELOP NEW CAPABILITIES}

An organization's focus on customers heightens the need for insights about their opinions, needs, and experiences. Ethnographic research is particularly valuable for eliciting the deep, detailed and nuanced understanding of what people do and why they do it that way. But user researchers who come from, and are trained in, ethnographic and design research perspectives can play a more significant role in organizations than merely bringing customer insights to the table; they can bring in new capabilities which originate specifically from their human-centered practices and world view.

Over the decade I've managed customer insights teams at Wells Fargo Bank the role and influence of researchers - particularly those with ethnographic and design research training and expertise - has expanded tremendously. We've gone from delivering quantitative and qualitative insights for discrete projects in a largely transactional fashion to orchestrating and facilitating organizational change. My academic training in organizational psychology may make me particularly attuned to this evolution but I have always felt that the true power of insights, particularly those from ethnographic research, lies in their ability to help organizations change course and achieve greater success by aligning more closely with customers and employees. To that end, I've always challenged the researchers on my teams to become great consultants, expert communicators, compelling storytellers and strong facilitators, in addition to being researchers. In this paper, I contend that researchers need to offer and organizations need to develop these capabilities to thrive in today's complex and constantly changing milieu:

- Embracing a Holistic Mindset

- Creating Shared Understanding

- Engaging in Design-oriented Problem Solving

These competencies are more than skills or tools; they are types of intelligence necessary to build humancentered organizations for today's networked world. In addition, dynamically changing environments call for the interpretation of new events and the re-interpretation of existing practices through learning (Boland, Tenkasi, \& Te'eni, 1994). These abilities increase "organizational learning," that is, the tactical and cultural adaptive capabilities, of organizations to respond to market and environmental forces (Senge, 1990). Organizational learning creates the capacity to develop new, or adapt old, competencies and innovate (Brown \& Duguid, 1991; Easterby-Smith, Snell \& Gherardi, 1998). In a customer-empowered, connected world exploding with change, business needs processes of reflection and learning to innovate. The capabilities described in this paper can also help business mitigate the risks associated with becoming out of touch with customer expectations and overall increase effective cross-functional collaboration and team effectiveness.

To help businesses thrive while meeting customer needs and expectations, researchers must become more than purveyors of insight; they must also act as knowledge brokers and change agents. But to fully inhabit these roles, researchers need to expand their own capabilities to include design thinking techniques, knowledge of organizational change models, and expert facilitation and consultation skills. This paper describes how researchers bring value beyond insights by infusing organizations with new ways of seeing and working, as part of a broader user-centered design process, and illuminates the more expansive role researchers can play as a result.

\section{EMBRACING A HOLISTIC MINDSET FOR PROBLEM SOLVING}

In discontinuously changing environments like the ones we now inhabit, a holistic perspective is critical for understanding both how things work and the underlying dynamics that tell us why. Today's organizations need insight into the entire customer lifecycle and help connecting the dots between siloed 
organizational departments. Ethnographers, as observers and interpreters of cultural systems, are accustomed and trained to look at systems holistically, to consider the entire ecosystem, or context, and not just the small piece that is impacted by a particular product or service. Holism maintains that the entirety equals more than its parts and contains properties that cannot be discovered through the analysis of parts. It stands in contrast with a reductionist world view.

Since the Industrial Era, most traditional corporations have operated out of a reductionist, mechanistic mindset. This way of thinking seeks to control complexity by breaking systems into smaller pieces in order to maximize efficiency. It works best in stable, routine, predictable environments. Mechanistic organizations typically rely on role specialization, with each function acting like parts of a machine, each doing the job they are meant to do but not much more. We are no longer living in this world. However, many organization structures still reflect Industrial Era assumptions and we often lack embedded work practices that help us to see whole systems (Notter \& Grant, 2011, pp. 132-134).

Forrester Research coined the term "customer experience ecosystem" to describe the complex system of people (employees, partners, and customers), products, services, technologies, and touchpoints that when examined as a whole, constitute the holistic customer experience (Bodine, 2013). Organizations need tools, such as customer journey maps, to help them view and understand their ecosystem and the customer's journey through it (Figure 1).

Ethnographers working in business are poised to bring the benefits of holistic, systems thinking to their companies through mapping the end-to-end customer, and sometimes employee, journey for a full view of the service experience.

\section{FIGURE 1 \\ THIS GENERIC CUSTOMER JOURNEY MAP SHOWS THE RANGE OF DATA DEPICTED, INCLUDING STEPS, TOUCHPOINTS, PAIN POINTS, AND EMOTIONS}

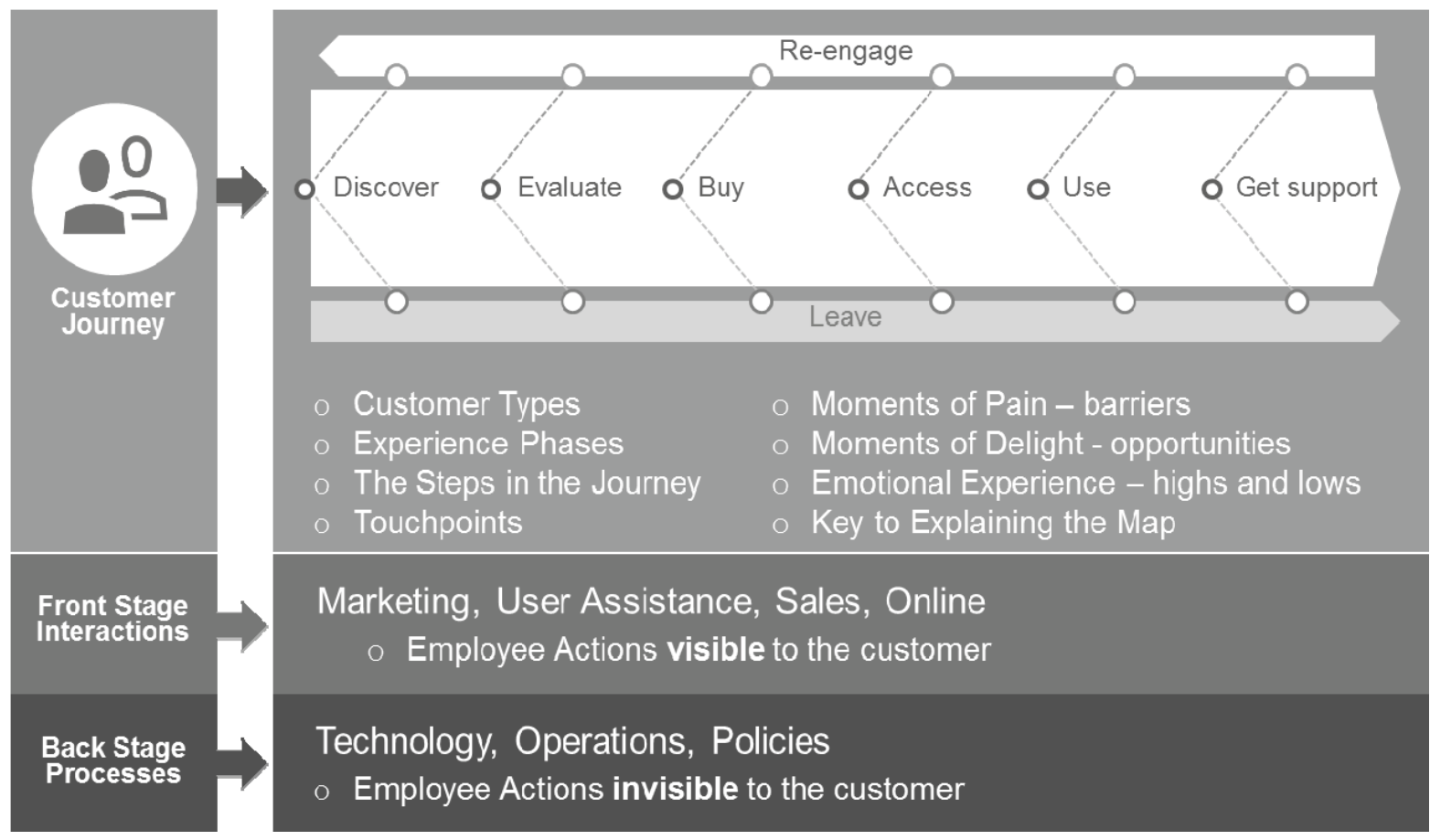

Ethnographic data is ideal input for mapping the customer experience journey, as it illuminates the particulars of the experience - the steps, phases, touchpoints, pain points, moments of delight, emotional experience - as well as the broader context beyond the moment when the product or service overlaps with the customer's life. 
Ecosystem and journey mapping, based on ethnographic data of what people do, say, and feel reveals the total experience as more than merely the sum of individual processes strung together across departments. Customers, as they traverse touchpoints across the lifecycle of their engagement, formulate their opinions of the overall experience and the meaning that the product or service carries in their lives. Understanding meaning rarely occurs from looking at individual interactions, but rather, by looking at the wider context of what someone needs or wants.

Being customer-centric invites and necessitates multifunctional conversations. Since the customer's experience inevitably traverses organizational siloes and functional area boundaries, ethnographic research initiatives tend to catalyze cross-group collaboration. Researchers will be required to develop organizational change and facilitation skills that encourage stakeholder participation, buy-in, sense making, and action-taking.

In 2011, I led an ethnographic study to understand how new customers interacted with the bank through all the available channels (branch, ATM, phone, online, etc.) and, for many of these group stakeholders, it was the first time they had really talked to one another (for the complete case study see: Beers, Stinson, Yeager, 2011). The study became the platform for opening up silos and bringing people together who had little occasion to collaborate previously. The opportunity to see the multichannel experience from the customer's point of view sparked new thinking and conversations which eventually led to tangible actions to improve the customer experience. The more complete view of the bank's touchpoint ecosystem encouraged cross-channel collaboration and led to new initiatives, including redesigning the new-customer onboarding program to address customer pain points and provide more support during "moments of truth," such as funding a new account or activating a new ATM card.

Just as companies don't often have a clear picture of their customer's behavior and motivation, they often have many blind spots regarding their own processes and how these fit together over the customer engagement lifecycle. Ethnographic research that matches behind-the-scenes activities with experience outcomes can illuminate the fragmentation and unintended poor experience that can ensue from siloed organizational structures and activities. For instance, we learned that new customers saw the branch as "ground zero" for getting all their questions answered but bankers were often left looking for answers themselves when the question involved another channel, such as Bill Pay in online banking. Bankers needed easier ways to connect with channel experts to obtain accurate information without being subjected to even more formal training. A channel hotline allowed bankers to quickly reach online experts who could explain the intricacies of a service. This allowed the banker to get help while maintaining face in front of the customer and reduced both hand-offs and the tendency for bankers to unintentionally pass along inaccurate information when they were not entirely sure of their answer.

Organizational learning and change occurs as the business reconciles its own, internally held assumptions - embedded in its strategies, processes, and structure - with how customers experience the results across the lifecycle of engagement. What does it all add up to? What's in and out of alignment with intentions? Where are the points of friction in the system? The organizational change implications are potentially massive when companies start to understand their customer's experience and their own processes holistically.

\section{CREATING SHARED UNDERSTANDING}

Good experiences happen at the intersection of customer needs, business goals, technology enablers, and the people that bring it all to fruition. It is a participatory process that requires teams of people to negotiate and reconcile all these elements across the ecosystem.

It is at this intersection that positive customer experiences that produce business value can be attained. But all these viewpoints and factors must be discussed, understood and reconciled "through dialogue in a human community" for true collaboration to occur (Boland, 1987, p. 377).

Researchers in corporations always represent just one discipline on a larger, multifunctional team. In an organization focused on creating digital experiences, such as the one that I work in, typical functions include product and project managers, business analysts, user experience designers, researchers, 
behavioral analytics analysts, content strategists, front-end developers, back-end database engineers, and technical architects. These teams are brought together to execute simple solutions for customers amidst tremendous complexity. We must combine our functional expertise, understand how we each contribute to the solution, and collectively ensure we are solving the right problems. Up-front time and attention must be devoted to alignment activities that result in shared understanding of what we are trying to achieve and why.

\section{FIGURE 2}

\section{GOOD EXPERIENCES ARE CREATED BY ALIGNING STRATEGIES, TECHNOLOGIES AND PROCESSES WITH CUSTOMER EXPECTATIONS}

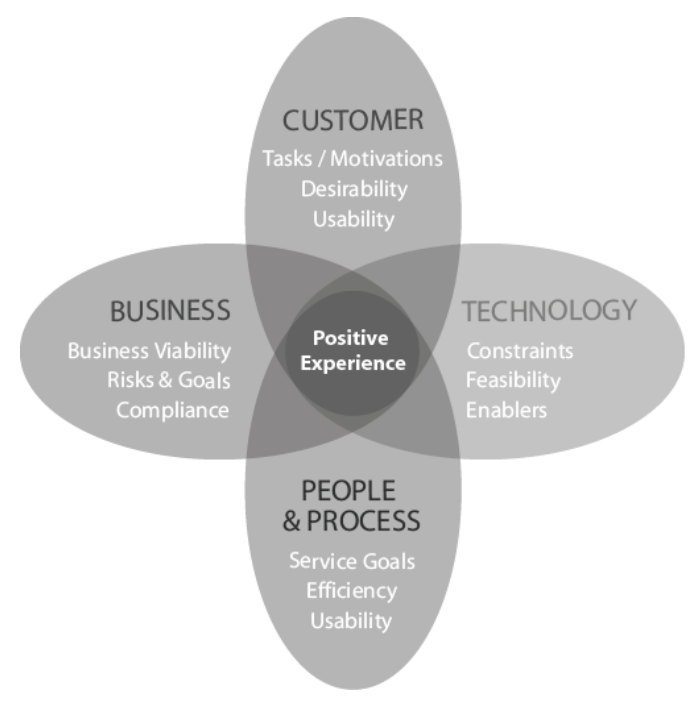

When all these different functions come together on a new project, the first job is to collectively understand the system - the current state of the product or service - the stakeholders involved on the project and their points-of-view, and what opportunities exist. Ambiguity abounds at this stage as team members are meeting, perhaps for the first time, roles and responsibilities are being established, and scope and timelines need to be defined.

In typical, business-led projects, scope is largely driven by timelines and costs, even when user needs and pain points are included in the mix. But, unless the multidisciplinary project team's early conversations are designed to include user needs, the scope definition phase can feel less like collaboration and more like the business functions handing off orders to the design team.

Let me illustrate with an example. Recently, a multifunctional team came together to redesign a complex commercial banking application. Business came to the table with a wish list of functional requirements they hoped to include in this project. This information was transferred into a draft of an official deliverable called a project scope document. The designers came to the project kickoff with their own questions based on years of working on this application but found little opening to dialogue and "open up" the items in the scope document, discuss what they meant, and how their implementation might improve the application.

Business and Design had the same goal - to reduce ambiguity and move the project forward - but different criteria and means for getting there. Business wanted to quickly lock in scope to obtain project funding and drive toward execution. But Design needed to more fully understand the terminology, opportunities, implications and tradeoffs being made before committing to scope. The team dynamic quickly became tense. Business felt Design was slowing down the project scope approval process by unnecessarily getting into more detail than was necessary at the start of the project. Design felt that we 
must "go slow to go fast" to achieve shared understanding, and create alignment about the problems to solve and how to solve them.

Just as good end-user experiences cannot be created without multifunctional collaboration, coming to shared understanding cannot happen without dialogue. Dialogue, like collaboration, equals more than the sum of its parts; it enables people to translate terminology for one another and develop alignment around a common purpose, critical precursors to coordinated action. Dialogue involves group interpreting and translating processes during which reconciliation between diverse perspectives and alignment can occur (Weick \& Van Orden, 1990). These activities are particularly important at the beginning of a project.

These conversations do not happen automatically, they have to be intentionally designed into the project's agenda. Herbert Simon in Sciences of the Artificial (1960, p. 55), defines design as the "transformation of existing conditions into preferred ones" and, in this case, what needed transformation was not just the software application but also the "us/them" dynamic between Design and the Business. Design convinced the product manager to try something new - use design thinking visualization techniques to facilitate alignment and, in so doing, transform scope definition from a business-led activity to one that was truly collaborative.

Researchers partnered with Design and Business to synthesize previous research. We also spent time pulling apart the draft scope document, which was packed with technical and business terminology that was ambiguous and unevenly understood across the multifunctional team. As the functions and features were isolated, we also attempted to translate the language into customer needs. Designers then further transformed this information by creating "opportunity cards" - simple visualizations of each proposed feature - for instance, "customize reports" or "personalization" - and used these cards to facilitate a whole-team discussion of what these terms actually meant, how important the team thought they were, and how difficult they would be to execute. A digital version was offered to remote participants who could track what was going on in the meeting room through conferencing software.

Being visual, instead of explanatory, allowed the multifunctional team to discuss the opportunities freely and focus on the intended end-user experience first before codifying them in the official project scope document. Facilitators presented the opportunity cards as individual cut outs so they could be moved around and used, hands on, by the team, in our in-person working session. They were not fixed, or final; they could be edited. They even had blanks for new and unforeseen opportunities.

After we gained group clarity on the proposed opportunity, we plotted the card along the $\mathrm{x}$-axis to prioritize importance relative to the other opportunities. Next, the facilitators drew the y-axis and the group prioritized again according to our collective sense of how difficult the opportunity would be to implement. We were calibrating user and business goals with organizational processes and technological capabilities through real-time, participatory dialogue.

The process and the outputs of this session were extraordinary; we went from polarized discussions between Business and Design to a multifunctional dialogue where true, shared understanding among all functions on the team was achieved. The facilitation invited participatory problem solving and provided a framework in which decisions could be made efficiently as a group. Using the opportunity cards as representations of potential aspects of the solution was a completely different experience for the team then reading through a flat scope document. We had time to discuss what the terms actually meant and to reconcile diverse interpretations. The visual and modular nature of the exercise further enhanced the discussion as participants could see how opportunity cards placed on the importance/difficulty matrix played off one another, something that would not have occurred if we dealt with each item in linear isolation. This workshop also led us to identify hypothesis for early Discovery user research. The team came out of the one-day session with a clear, shared understanding of what the terms meant, their relative priority based on importance and difficulty, and a list of hypotheses to explore with users. 
FIGURE 3

OPPORTUNITY CARDS WERE CREATED BY "PULLING APART" THE SCOPE DOCUMENT AND TRANSLATING THE FEATURE AND FUNCTION TERMINOLOGY INTO LANGUAGE THAT DESCRIBED THE CUSTOMER'S NEED.

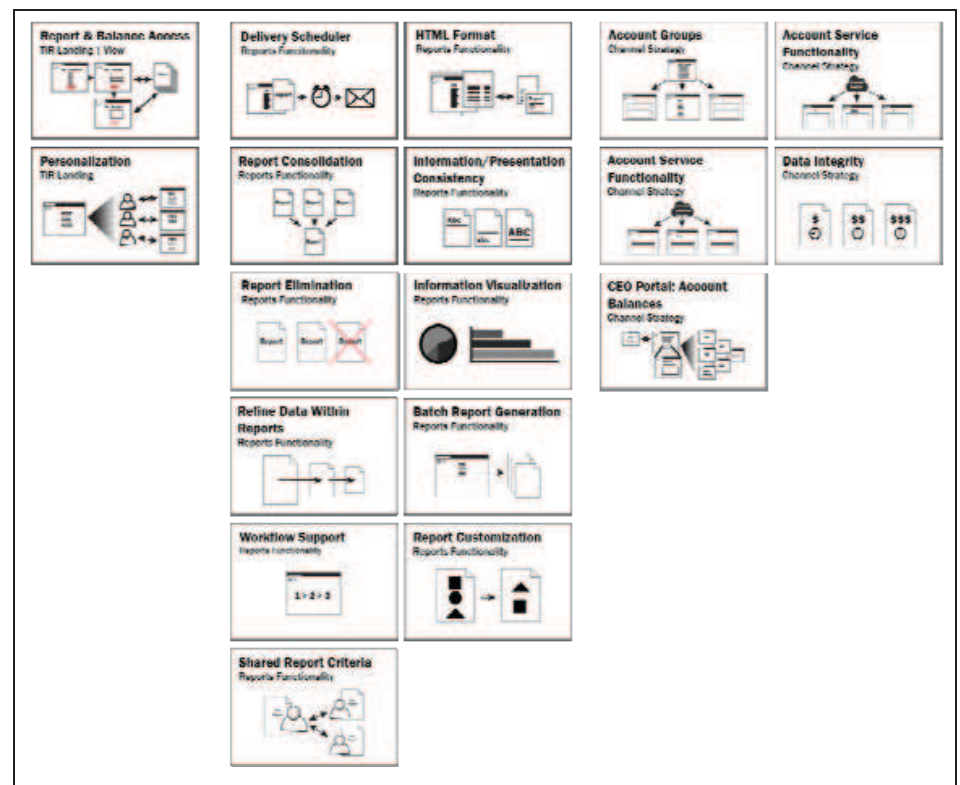

FIGURE 4

OPPORTUNITY CARD DETAIL FOR BATCH REPORT GENERATION: EACH OPPORTUNITY CARD HAS A SIMPLE GRAPHIC REPRESENTATION, SYMBOLIC OF THE OPPORTUNITY AND A VERY SHORT DESCRIPTION OF THE FUNCTION, WITH A PURPOSE STATEMENT AND SOME RELATED OPPORTUNITIES.

\section{Opportunity: Batch Report Generation}

Description: Provide ability to generate multiple reports simultaneously.

Purpose/pain relieved: Simplified process of requesting multiple reports. Related Opportunities: Report/Balances Access, Share Report Criteria, Personalization, Report Customizing

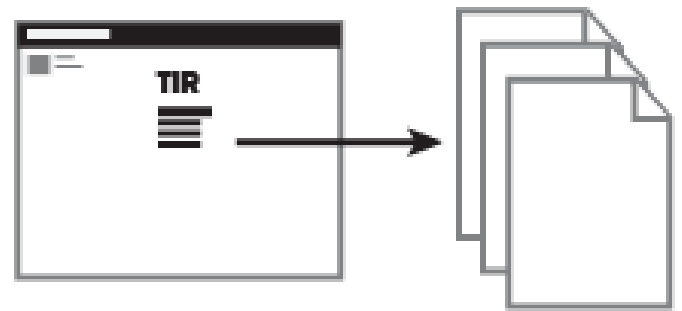




\section{FIGURE 5 \\ IMPORTANCE / DIFFICULTY MATRIX}

(The Importance / Difficulty Matrix exercise was taught to us in the context of human-centered facilitation training taught by the LUMA Institute. More about LUMA can be found on their web site: http://www.luma-institute.com/)

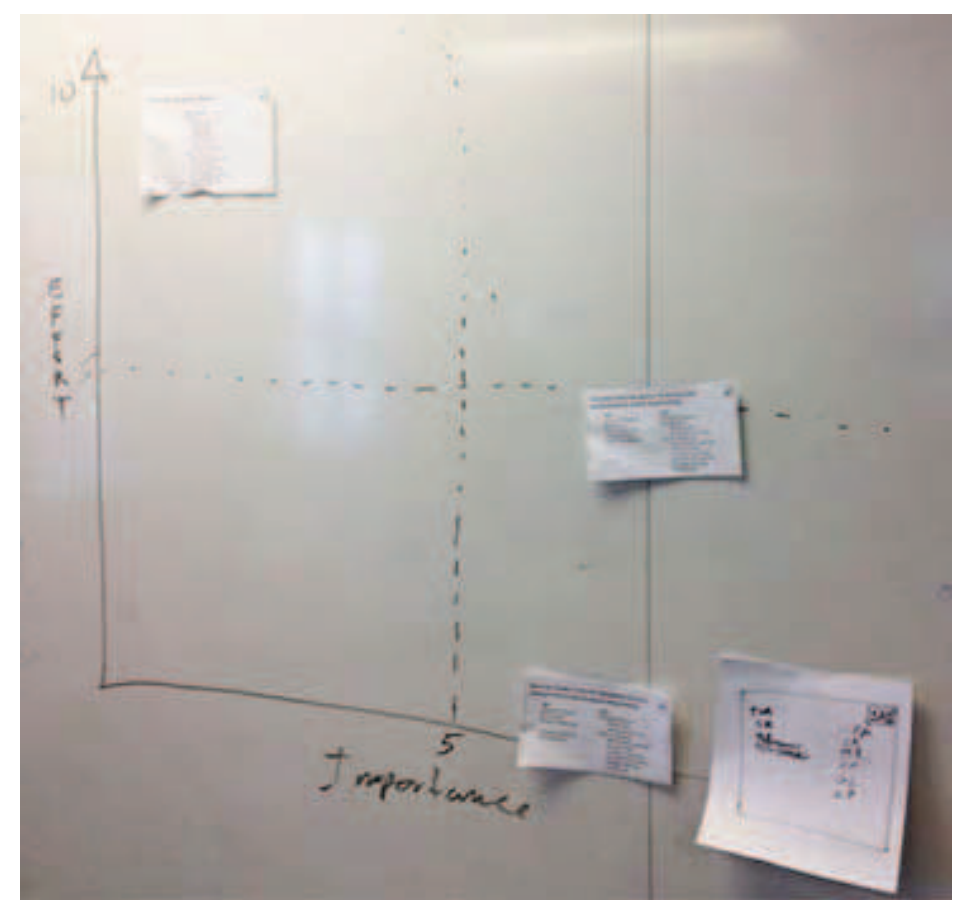

Even though this was more of a design-led, rather than a research-led workshop, the tight collaboration between Design and Research contributed to the positive outcome by grounding the opportunities in previous research findings and taking the hypotheses as a next step to be carried out by Research. In this example, combining a holistic mindset with an emphasis on dialogue to achieve shared understanding resulted in team alignment and commitment to shared objectives and next steps.

\section{DESIGN-ORIENTED PROBLEM SOLVING}

The shift of power from business to people signals a need for organizations - and the teams of employees within them - to transform how they work together and produce value. User-centered design (UCD) is a proven approach and set of methods that can support organizations on their path to become more customer-centric (Beers \& Whitney, 2006). UCD is a product development process that involves learning from and incorporating end-user feedback throughout the entire product lifecycle, giving researchers a large role to play. For product- or technology-centric organizations, user-centered design methodology can represent a radical shift in mindset and work practices. Essentially, UCD puts people and their needs, goals, and tasks on par with the organization's business goals and technology capabilities:

The chief difference from other product design philosophies is that user-centered design tries to optimize the product around how users can, want, or need to use the product, rather than forcing the users to change their behavior to accommodate the product.

http://en.wikipedia.org/wiki/User-centered_design

The rise of UCD practices in business acknowledges that products and services need to work well for the people who use them. 
In today's experience-driven economy, UCD helps to mitigate risk of an unsuccessful product by getting the noise out of the system earlier. Research contributes to this goal by going directly to users to observe and gather feedback using in-process prototypes and helping the team learn so it can iterate the design of the product toward an optimal solution. At Wells Fargo, our generic UCD process model looks like this:

\section{FIGURE 6 \\ USER-CENTERED DESIGN PROCESS}

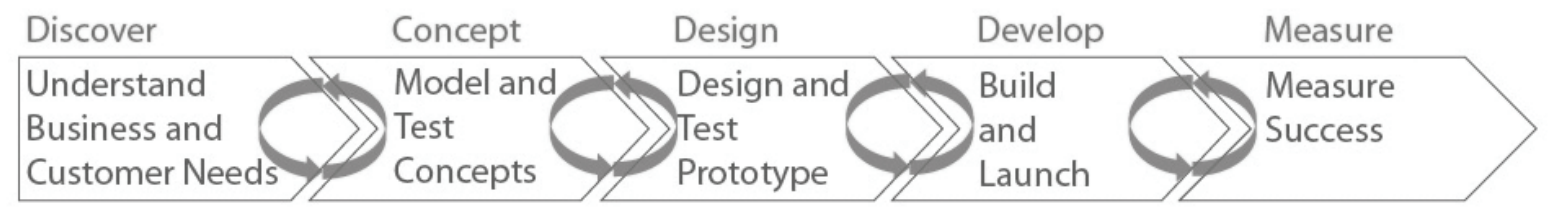

The circular arrows represent iteration based on learning from feedback. The iterative nature means that UCD is inherently an organizational learning process.

Learning occurs when "out there" insights gathered by Research are brought in as points of comparison with internally held organizational assumptions. Comparing people's "out there" expectations and experiences to "in here" organizational assumptions strikes at the heart of what is most valuable about customer research. Ethnographic insight is most powerful in helping organizations learn and innovate when the "what" of people's lived experience is combined and calibrated with the "how" of meeting business goals. When this comparative aspect is orchestrated intentionally it has the power to transform organizations.

Cycles of iteration through learning and reconciling "out there" perceptions with "in here" assumptions are supported by the concept of divergence and convergence, which is intrinsic to the UCD process.

\section{FIGURE 7}

\section{USER-CENTERED DESIGN INVOLVES CONVERGENT AND DIVERGENT ACTIVITES}

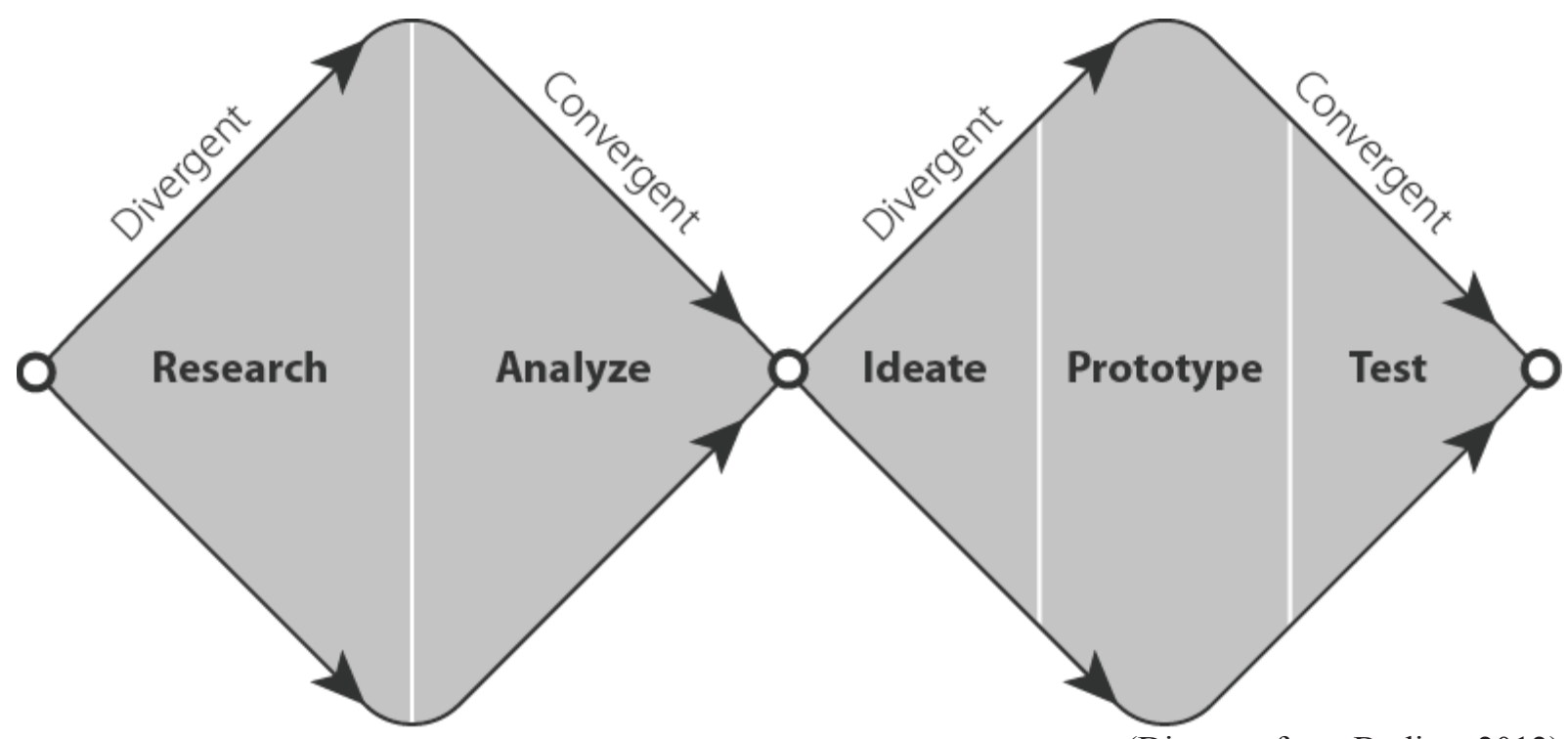

(Diagram from Bodine, 2012) 
The divergent and convergent double-diamond diagram is likely familiar to ethnographic researchers and designers practicing UCD. It begins with a point of focus, such as an area of inquiry, but then diverges as the data, and the complexity of making sense of that data, floods in. The analysis process leads us back out of ambiguity toward honing in on understanding context, the critical elements of experience, and potential problems to solve. Kerry Bodine, from Forrester Research, writes:

Designers often describe the end-to-end design process as a double diamond. It starts at a singular point - the initial focus for the project - but quickly diverges as the research uncovers new insights and potential problems to solve. The process converges to the midpoint as teams synthesize the research findings and reframe the project focus. The process diverges again as teams brainstorm a broad range of possible solutions and start to prototype. Lastly, refinement through multiple rounds of prototyping and testing converges the process to its final point: the design solution. (Bodine, 2012)

A story illustrates the power of juxtaposition and comparison along with the activities of divergence and convergence to ensure that teams are aware of the ecosystem dynamics at play.

Years ago, at a consulting firm where I held the title "Experience Modeler," a team set out to redesign the web site of a non-profit foundation offering resources for parents whose children experienced learning disabilities. Following a UCD process, the team sent researchers to conduct ethnography - a divergent activity that casts the inquiry net wide - with mothers of kids with learning disabilities. The rich insights offered portraits of moms who worked tirelessly to get their kids the medical, therapeutic, and educational resources that they needed; they were true advocates and warriors on behalf of their children, accustomed to encountering obstacles and refusing to take "no" for an answer.

The insights into the mom's experiences were successful in providing designers with empathy and context from which to redesign the site. But researchers had cast the net wider than just the moms and had also conducted stakeholder interviews with the foundation's staff. They noticed that the staff often spoke about these mothers in negative terms, such as referring to them as "rabid" or "combative." Researchers brought both sets of data to a sense-making, analysis workshop. The leadership was shaken by the dissonance between the foundation's mission and the staff's attitudes toward the mothers they served. By taking a broad, holistic perspective and casting the inquiry net wide - diverging - the project team was able to converge on the decision to work on resolving the negative conception of its target audience and improving the foundation's internal culture before moving forward with the redesign. This example also illustrates the point that insights can catalyze organizational change that then thrusts researchers into the dual role of change agent.

Another type of convergence/divergence activity involves synthesizing the massive amount of data that comes out of ethnographic research into visual representations called experience models. This is where academically trained researchers must expand their capabilities and, sometimes, enlist the help of their design colleagues. Experience Models visually crystallize the current state and suggest opportunities for better meeting people's needs - they often act like headlights for the product teams that use them.

These models communicate the patterns of how people organize their experience and represent the culmination of rigorous data analysis. Experience models are typically arrived at and agreed upon collaboratively, building veracity into the analysis process and buy-in for the findings and recommendations.

Experience models that ring true within the organization and thus live on, can be said to attain experiential significance:

Experiential significance is a transformative analogue to statistical significance. It is felt through rigorous, collaborative analysis when an emerging model is both easily grasped by organizational stakeholders and resonates with data-driven truths and intuitive "rightness." Models such as these are mental tools that can provide a "Eureka!" spark for new thinking. (Cayla, Beers, \& Arnould, 2014, p. 58)

These models also provide a container for the ethnographic insights to live on, providing shorthand for teams to refer to and use the learning for years to come. 
By example, the simple model shown in Figure 8 was dubbed the "View/Do" loop within Wells Fargo and communicated our key findings that when people are doing their routine financial tasks they are largely on automatic pilot and do not often switch into "learning" or "discovery" mode when it comes to exploring online banking.

\section{FIGURE 8 \\ EXPERIENCE MODELS ARE THINKING TOOLS}

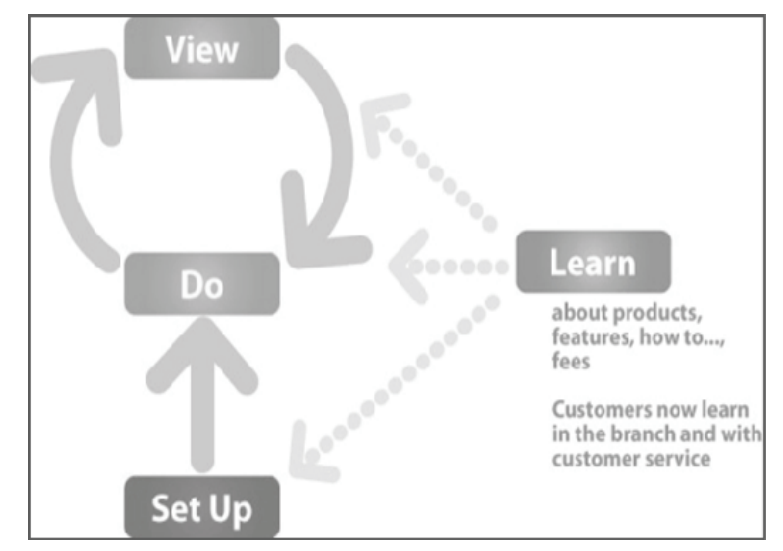

This experience model showed highlighted that information and functionality available on the site was not discovered within the user's routines and it helped crystallize the problem we were trying to solve within a redesign - undiscovered and, thus underutilized, functionality that lived outside this loop - and it became shorthand for pursuing a strategy of in-context content and features. In fact, the project team tasked with redesign embraced the model so whole heartedly that they riffed off the model's View/Do label and named the overall project VooDoo.

For models to attain experiential significance, or act as an "experiential guidepost" they must be easy to grasp and have resonance within the organization (Blomberg, Burrell, \& Guest, 2009). Models represent a point of convergence in the ethnographic process, distilling data and findings into "boundary objects" that team members can point to, discuss, and use to arrive at shared understanding (Star \& Griesemer, 1989). In my work, I have repeatedly seen that a visual representation - such as an experience model or the opportunity cards discussed earlier - do a superior job of generating discussion and agreement, as opposed to discussion alone or narrative, non-visual documents.

\section{CONCLUSION}

If we are going to create organizations that can thrive in today's more social world... we don't need our organizations to be better machines. We need our organizations to be more human. (Notter \& Grant, 2011, p. 95)

In complex, large organizations, multifunctional project teams are the rule. Every function - be it engineering, product management, design, marketing - comes in with particular expertise and focus. This expertise and focus acts like a lens that colors how the team member perceive and understand the issues and problems they have come together to solve. Activities dedicated to understanding the ecosystem, translating viewpoints, and learning through experimentation and iteration are critical to team alignment and, ultimately, successful execution.

Researchers have unique perspectives, skills, and a critical role that they can occupy to help organizations become more human. The capabilities described in this paper - embracing a holistic mindset, creating shared understanding, and design-oriented problem solving - necessitate that researchers expand their activities and self-perception beyond data collection, analysis and reporting. The 
ethnographer's role can, and needs to, progress from mere researcher to facilitator, knowledge broker, and change agent. We have what it takes to help organizations transform and succeed in today's connected, social, and people-centered world.

\section{REFERENCES}

Beers, R., Stinson, T. \& Yeager, J. (2011). Ethnography as a Catalyst for Organizational Change: Creating a Multichannel Customer Experience. Ethnographic Praxis in Industry Conference Proceedings.

http://epiconference.com/2012/sites/epiconference.com.2012/files/attachments/article/add/EPIC2 012-Proceedings.pdf.

Beers, R. \& Whitney, P. (2006). Ethnographic Insight to User-centered Design Tools. Ethnographic Praxis in Industry Conference Proceedings. http://onlinelibrary.wiley.com/doi/10.1111/j.15598918.2006.tb00043.x/pdf.

Boland, R. J. (1987). The in-formation of information systems. In R. J. Boland \& R. A. Hirschheim (Eds.), Critical Issues in Information Systems Research. New York: Wiley, 363-94.

Boland, R. J., Tenkasi, R. V., \& Te'eni, D. (1994). Designing information technology to support distributed cognition. Organization Science, 5 (3), 456-475.

Bodine, K. Q\&A: Customer Experience Design. June 22, 2012. Forrester Research. http://www.forrester.com/Executive+QA+Customer+Experience+Design/fulltext//E-RES75961.

Bodine, K. (2011. Updated, 2013). The Customer Experience Ecosystem. Forrester Research. http://www.forrester.com/The+Customer+Experience+Ecosystem/fulltext/-/E-RES59115.

Blomberg, J.; Burrel, M. \& Guest, G. (2009). An Ethnographic Approach to Design. In: HumanComputer Interaction: Development Process (Google eBook). Andrew Sears \& Julie A. Jacko, Eds. CRC Press, 964-987.

Brown, J. S., \& Duguid, P. (1991). Organizational learning and communities-of-practice: Toward a unified view of working, learning, and innovation. Organization Science, 2, 40-57.

Cayla, J., Beers, R. \& Arnould, E. (Winter 2014). Stories that Deliver Business Insights. MIT Sloan Management Review. V55. No. 2, 55-62.

Cooperstein, D. (2013). Competitive Strategy In The Age Of The Customer. Only Customer-Obsessed Enterprises Can Survive Disruption. Forrester Research. http://www.forrester.com/Competitive+Strategy+In+The+Age+Of+The+Customer/fulltext/-/ERES59159.

Easterby-Smith, M., Snell, R., \& Gherardi, S. (1998). Organizational learning and learning organization: Diverging communities of practice? Management Learning, V29, 259-72.

Neumeier, M. (August 13, 2008). Designing the Future of Business. Business Week. http://www.businessweek.com/stories/2008-08-13/designing-the-future-of-businessbusinessweekbusiness-news-stock-market-and-financial-advice.

Merchant, N. (2012). 11 Rules for Creating Value in the Social Era. Cambridge, MA: Harvard Business Press Books.

Notter, J. \& Grant, M. (2011). Humanize. How people-centric organizations succeed in a social world. Indianapolis, IN: Que Press.

Senge, P. M. (1990). The Fifth Discipline: The Art Of The Learninng Organization. New York: Doubleday.

Herbert Simon, (1969). Sciences of the Artificial. Cambridge.

Star, S. L. \& Griesemer, J. R. (1989). Institutional ecology, 'translations' and boundary objects: Amateurs and professionals. In: Berkeley's Museum of Vertebrate Zoology. Social Studies of Science, V19, 387-420.

Stickdorn, M. \& Schneider, J. (2010). This is Service Design Thinking. New York: Wiley, 30-33.

Weick, K. \& Van Orden, P. (1990). Organizing on a global scale. In N. Tichy, (Ed.), Human Resource Management, V29, 49-62. 